\title{
How to survive as a pioneer species in the Antarctic benthos: Minimum dispersal distance as a function of lifetime and disturbance
}

Authors:

\begin{tabular}{|c|c|}
\hline Michael Potthoff ${ }^{1}$ & mpotthoff@awi-bremerhaven.de \\
\hline Karin Johst ${ }^{2}$ & karin.johst@ufz.de \\
\hline Julian Gutt $^{1}$ & igutt@awi-bremerhaven.de \\
\hline
\end{tabular}

${ }^{1}$ Alfred Wegener Institute for Polar and Marine Research,

Columbusstr,

27568 Bremerhaven, Germany

${ }^{2}$ Department of Ecological Modelling,

UFZ Centre for Environmental Research Leipzig-Halle, PO Box 500135,

04301 Leipzig, Germany

This article has been published in

POLAR-BIOLOGY. JUN 2006; 29 (7) : 543-551

DOI 10.1007/s00300-005-0086-1

The original publication is available at www.springerlink.com

This is an author-created version of the unchanged article according to the copyright agreement between the authors and Springer publishing. 


\subsection{Abstract}

Very few details exist concerning the dispersal traits of Antarctic species and dispersal distances in particular are mostly unknown. Especially the general low number of mesoplanktonic larvae has caught attention, leading to the formulation of Thorson's rule. From this concept, originally concerning only trophic aspects, sometimes a reduced dispersal distance is deduced. Using a generic simulation model we show that in a benthic habitat exposed to iceberg scouring even short dispersal phases of few hours are sufficient for a pioneer species to persist. This is very surprising for a pioneer species that should be able to disperse widely and colonise distant disturbed areas that are free of superior competitors. Our model revealed that the reason for this is the non-linear dependence of the dispersal distance on the disturbance regime and on species longevity. Thus, it is the combined effect of life history and disturbance traits which is important here: a sufficiently high disturbance frequency due to iceberg scouring and a long individual lifetime due to the low temperature decrease minimum dispersal distances required for persistence and thus coexistence and present an additional explanation for the relative rarity of planktonic larvae. 


\subsection{Introduction}

The Weddell Sea benthos is relatively diverse (Clarke and Johnston 2003; Gutt et al. 2004), shaped by disturbance events due to scouring icebergs, which form one characteristic of the system (Arntz et al. 1994; Brown et al. 2004; Gutt and Piepenburg 2003; Gutt et al. 1996). Recent field work on the succession after iceberg scouring revealed unpredictable primary succession stages ending in a local climaxlike community in a site (Ragua-Gil et al. 2004; Teixido et al. 2004). Succession is slow, possibly over hundreds of years (Gutt and Starmans 2001). Several life history traits determine such a succession of which dispersal is one of the most important (Bolker and Pacala 1999). In terrestrial systems dispersal or dispersal shadows can be measured by direct observation, tagging, traps and molecular markers. In aquatic systems the methods theoretically work in the same way. However, the reduced accessibility of these systems (due to visibility, depth and remoteness) make the application difficult when a relatively high spatial and temporal resolution is required. This is especially the case when tiny mesoplanktonic larvae, as the predominant dispersal form among marine species (Muko and Iwasa 2000; Roughgarden et al. 1988), have to be considered. Generally, larvae may stay in the water column for less than one minute or have an extended pelagic phase of up to several months (Largier 2003; Shanks et al. 2003). Although the dispersal distance seems to be correlated with the length of the pelagic phase (Shanks et al. 2003), recent work showed that larvae often settle close to their parents, regardless of a long pelagic phase (Fisher 2005; Jones et al. 2005; Todd 1998). Nevertheless, almost nothing is known about the actual dispersal distances of most marine species (Grantham et al. 2003). Summarising the current literature on pelagic larvae in Antarctic waters (see Bhaud et al. 1999; Stanwell-Smith et al. 1999; Shreeve and Peck 1995; Absher et al. 2003 and Sewell 2005), larval density in the austral summer is seemingly low. A decline in pelagic dispersal stages with indirect development and increase in lecithotrophic larvae and direct development with higher latitudes is known as "Thorson's rule" (Mileikovsky 1971). This is often supposed to reduce the potential dispersal distance simply by an assumed shorter dispersal time for lecithotrophic larvae and direct development. The ecological constraints leading to such shifts are not well understood, but recently Thatje et al. (2005) attempted to link these to the glacial history of Antarctica. However it is not entirely clear, how disturbance regime and 
environmental conditions may have influenced the life history traits of Antarctic species.

Especially the combined effects of the disturbance regime and lifespan on the dispersal traits are uncertain. The interplay of these two factors is of great interest as they influence the coexistence of species and communities. In the Antarctic the constant low temperatures are considered to slow down life in the majority of species (Arntz et al. 1994), but there are also some normal or comparably fast growing forms (Barnes 1995; Brey et al. 1998; Kowalke et al. 2001). As longevity fosters the local competitive ability of sessile organisms, it can cause the dispersal distance to decline. This is the usually assumed trade-off between colonisation and competitive ability to ensure the regional coexistence of species (Tilman 1994). But qualitative and quantitative knowledge about the functional form of this trade-off and about the dependence on the disturbance regime are lacking.

The main aim of this study is to investigate the combined effects of the dispersion of larvae and the longevity of adults on the persistence of a population of pioneers under the influence of disturbances. How far must a pioneer species disperse under a given disturbance regime to persist in the competition with a superior competitor? How do both the lifetime of the organisms and the disturbance rate influence this minimum necessary dispersal distance for persistence? Experimental field work to answer these questions is nearly impossible to carry out. Computer simulation models provide an alternative way. We use a spatially explicit simulation model to study these questions and apply the results to the benthic assemblages of the Weddell Sea. In particular, we want to find out whether the general trend of dispersal distances supports or contradicts Thorson's rule.

\subsection{Methods}

The dispersal distance being sufficient to reach at least the closest suitable habitat should be a function of the process that generates such habitats, in other words of the disturbance regime. Therefore we first analysed the spacing of disturbed areas in dependency on the disturbance regime. In a simulation model we determined the mean distance between the borders $\left(D_{B D}\right)$ of two nearest neighbouring disturbed areas. Assuming circular disturbances allowed us to calculate $D_{B D}$ using the distance from centre to centre $\left(D_{C}\right)$ and the radius $r$ of the disturbances. Therefore first $D_{C}$ had to be calculated in dependency on the disturbance frequency. 
In a second simulation we determined the minimum dispersal distance $\left(d_{\min }\right)$ for a pioneer species to persist and coexist with a superior competitor. This was done again for different disturbance regimes and in respect to the lifespan of the pioneer. This enabled us to relate $d_{\min }$ and $D_{B D}$ (respectively the disturbance regime).

In a third step we then applied our theoretical results to Antarctic pioneer assemblages. We estimated a minimum dispersal distances a pioneer species needs to persist locally on the continental shelf under current disturbance conditions. For this we used knowledge about disturbance regimes and species life history traits of benthic assemblages composed of sedentary animals derived from the literature.

\subsection{Computer simulations}

\subsubsection{Habitat spacing}

To compute the distance from border to border $\left(D_{B D}\right)$ first the distance from centre to centre $\left(D_{C}\right)$ of two nearest neighbouring disturbances must be determined. To do this a number $N$ [per time step] of circular disturbances of a given radius $r$ were placed randomly within a square area (1 unit length) and $D_{C}$ was measured. This was done for different $N(N=2,3,4,6,8,10,14,18,24,30,36,44,50,60,80,100)$ and with each 1,000 replicates. $D_{C}$ only depends on the disturbance frequency $N$ and a curve fitting allowed us to compute $D_{C}$ for any given $N$. The mean distance from border to border $\left(D_{B D}\right)$ depends on $D_{C}$ and the disturbance radius $r$ and can be computed as

$D_{B D}(N ; r)=D_{C}(N)-2^{*} r$

Note that both $D_{B D}$ and $D_{C}$ are relative to the box scale. As $D_{C}(N)$ is constant for a fixed $N, D_{B D}(N ; r)$ is a strait falling line with a slope of -2 . 


\subsection{Minimum dispersal distance of a pioneer species $\left(d_{\min }\right)$}

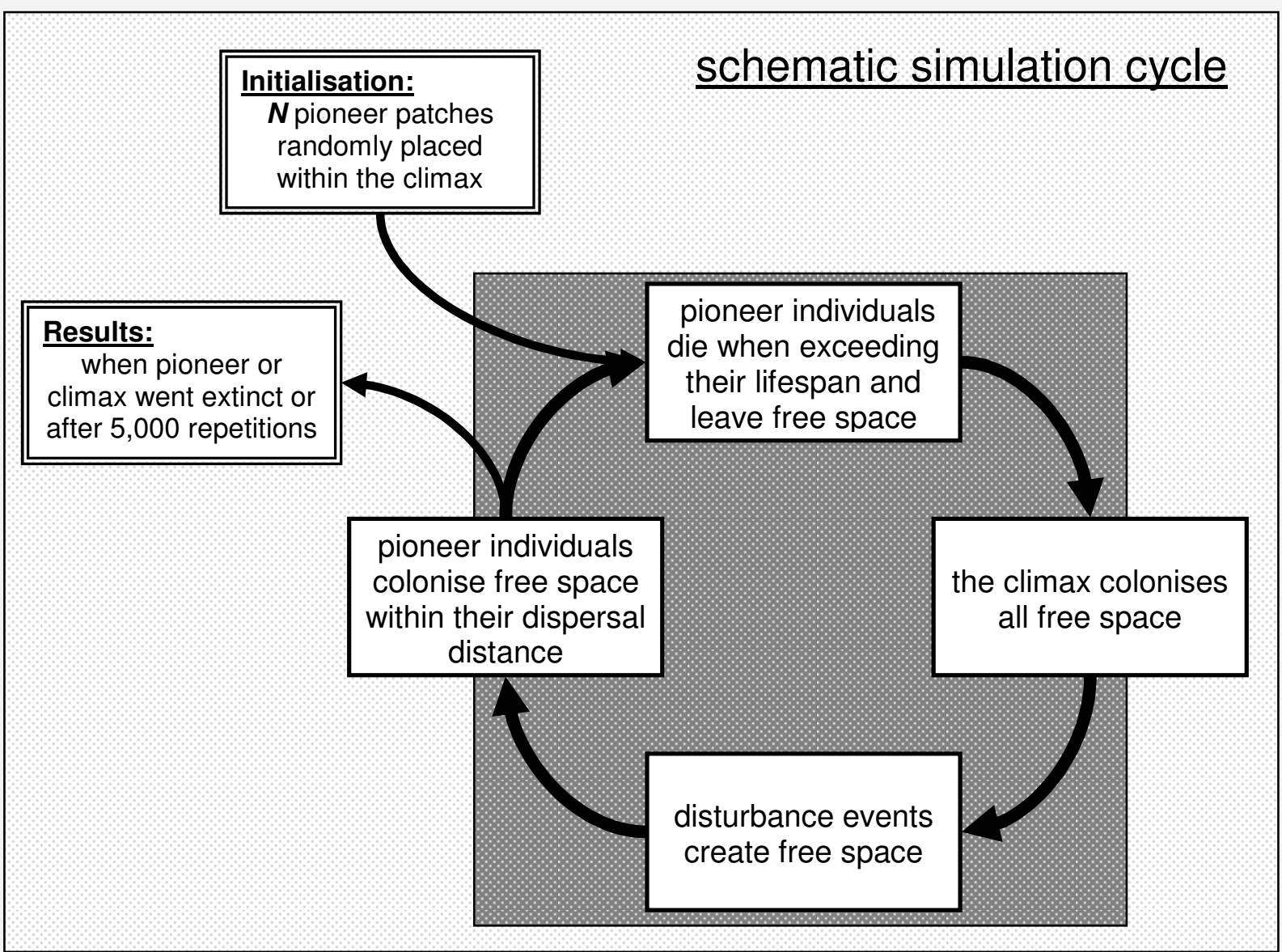

Figure 1 Model simulation cycle. After the initialisation the simulation is performed for 5,000 time steps or until a break condition.

To determine the minimum dispersal distance for a pioneer species to persist and coexist with a superior competitor a grid-based model with periodic boundary conditions was used. This means that any object leaving the grid on one side reenters the grid on the opposite side. This avoids disadvantages for individuals at the borders. The spatial dimension of the grid was $100 \times 100$ grid cells. A cell could be inhabited by either a pioneer species, defined by its dispersal distance (measured in grid cells) and lifespan (in time steps), or the climax assemblage, characterised by its competitive superiority (once the climax assemblage has taken over a position it will remain there unless the space is opened by disturbance). Figure 1 shows a flowchart of the simulation cycle. Within one simulation the grid was initially filled with $N$ randomly placed circular patches with the radius $r$, colonised by the pioneer species. 
The remaining cells were assigned to the climax. In each of the simulated time steps the age of any pioneer individual increased. Once it reached its maximum age it died and the grid cell became empty. Subsequently, all empty cells (empty due either to the death of the pioneers or to not having been colonised) were overgrown by the climax because of its superiority. Then disturbance was simulated by a given number $N$ of circular disturbances with the radius $r$, randomly placed over the entire grid. Affected cells were cleared of any inhabitants. This free space was potentially colonised by the recruits (of age 0 ) of any pioneer individual when within its dispersal range. For simplicity reason we assumed dispersal to be equal in all directions and that the amount of larvae was not limited. Thus any available habitat within a circle according to the dispersal distance could be colonised by the pioneer.

These steps were repeated either until the pioneer or the climax assemblage had gone extinct or 5,000 steps had been executed and both pioneer and climax still coexisted. Simulations typically reached an equilibrium within fewer than 100 time steps. The minimum dispersal distance for the persistence of the pioneer was determined by simulations with dispersal distances ranging from 1 (local) to 50 cells (quasi global dispersal) in two cell steps. These procedures were repeated with 100 replicates each. These calculations were repeated for varying disturbance regimes (function of radius and frequency) and lifespans $(1,2,4,8,16,32,64)$ of the pioneer. 


\subsection{Results}

\subsubsection{Habitat spacing}

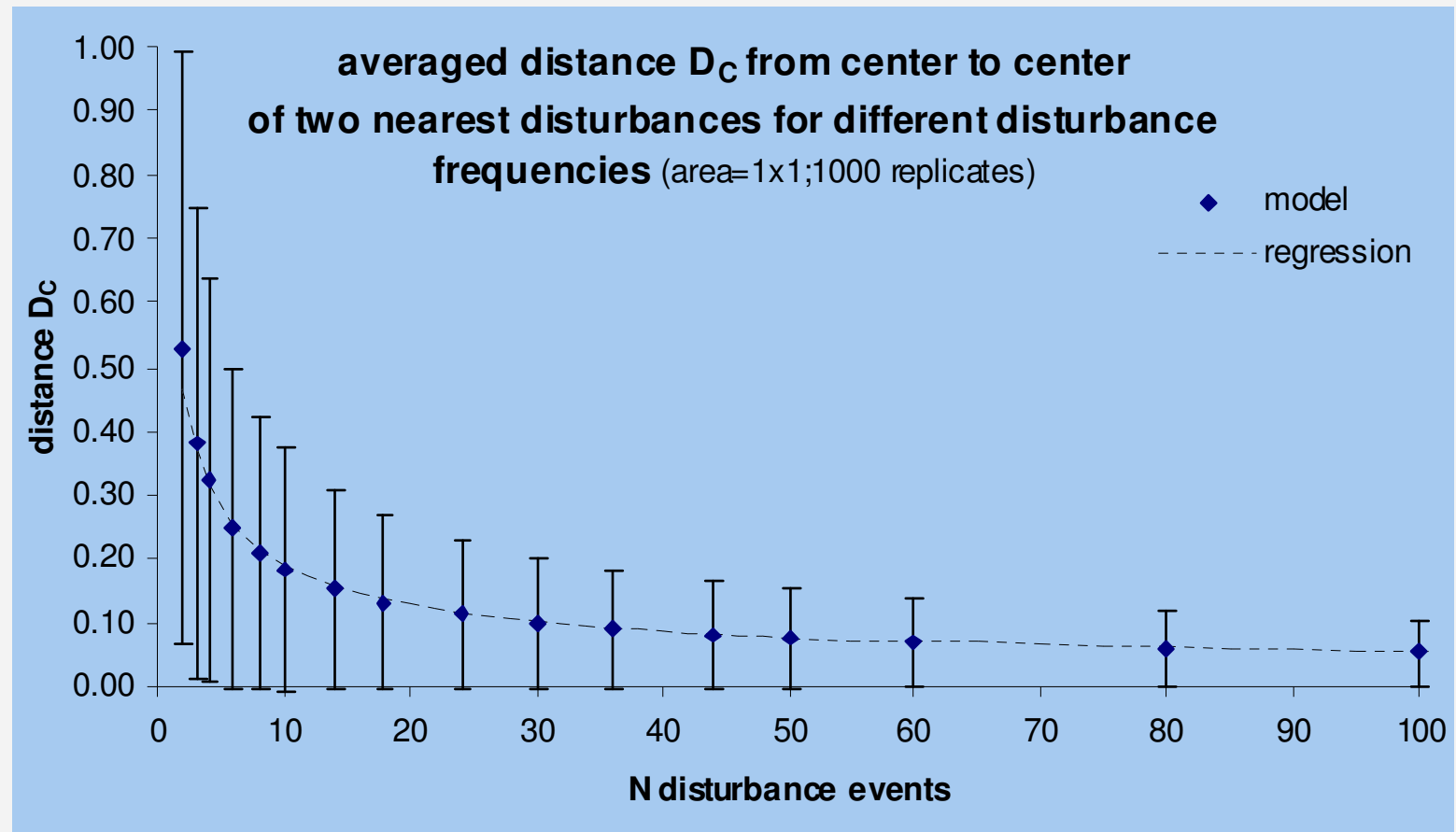

Figure 2, Distance $D_{c}$ from centre to centre of the nearest disturbance for different disturbance counts per time step. The distance decreases hyperbolically with increasing $\mathrm{N}$.

Figure 2 shows the mean and standard deviation for the empirical determined values of $D_{C}$ for different $N$. $D_{c}(N)$ has the form of a hyperbola. Curve fitting resulted in the following formula:

$$
D_{c}(M)=\left(0.681 * N^{-0.557}\right) \quad\left[r^{2}>0.99, N=\text { disturbance frequency }\right]
$$




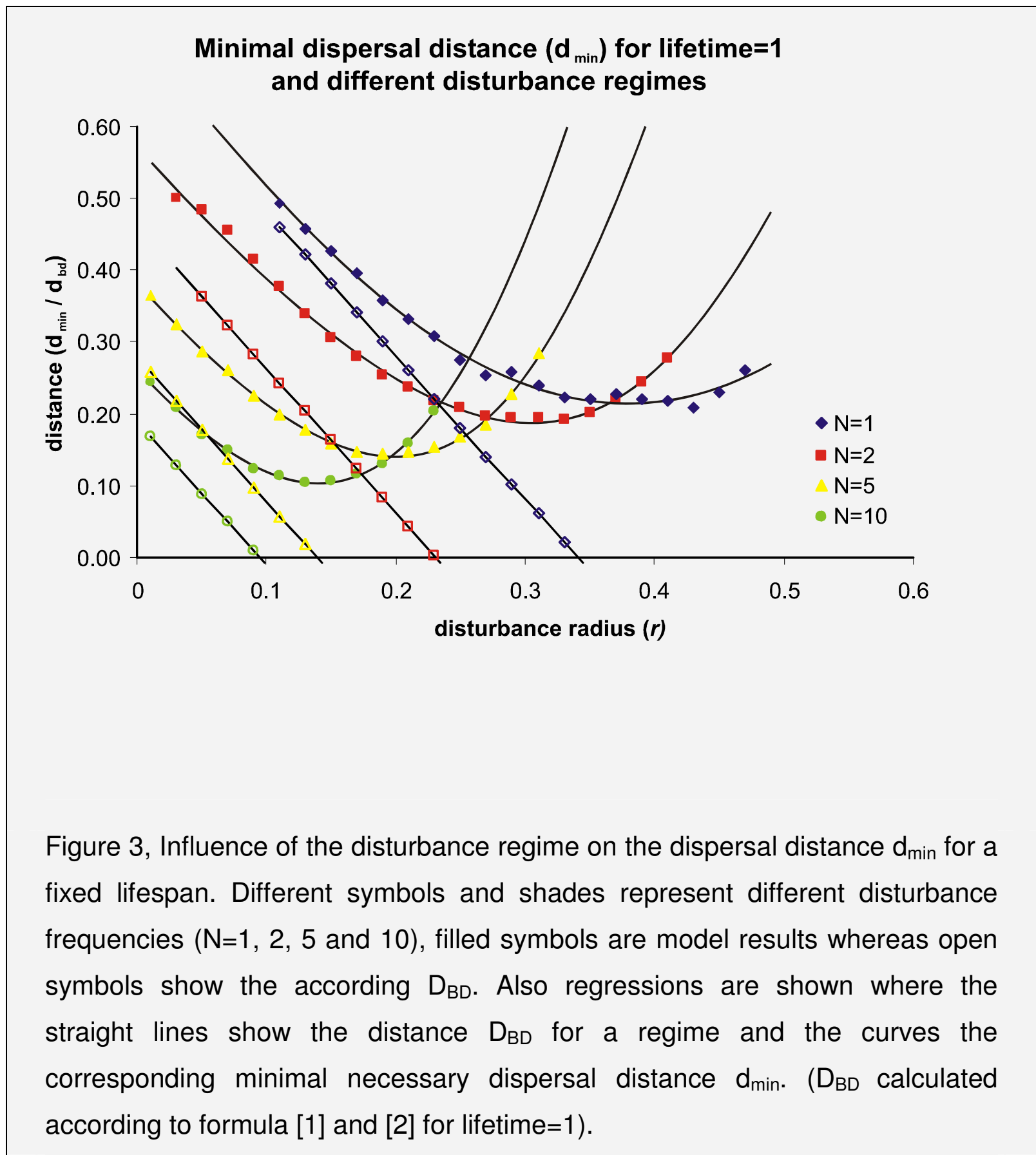

The closed symbols in Figure 2 show the minimum dispersal distance $\left(d_{\min }\right)$ of the pioneer needed for the coexistence with a superior climax as a function of the disturbance radius ( $x$-axis) and for different disturbance frequencies (different symbols). The open symbols represent the according distance $D_{B D}$ derived from formula 1 and 2 . Figure 2 shows only the data for lifetime $=1$ but other lifetimes result in similar pictures although with shorter distances (see below) and the general 
features are the same. For better readability the symbols are connected by fitted lines (see appendix for detailed values).

$d_{\min }$ is always higher than the according $D_{B D}$ (Figure 2). The curves of $d_{\min }$ are ushaped and opened upwards. For small disturbance radii $d_{\min }$ first progresses nearly parallel with $D_{B D}$ and decreases with increasing disturbance radius. With further decreasing $D_{B D}$ the deviation between $D_{B D}$ and $d_{\text {min }}$ increases. When $D_{B D}$ approaches zero (disturbed areas start to overlap), $d_{\min }$ raises until a value around $d_{\min } \sim 0.35$. Above these value no coexistence occurred in the model because both the pioneer and the climax went extinct. For regression, coefficients and goodness of fit for all parameter sets see Table 1 in the appendix.

\subsubsection{Dependency of the minimum dispersal distance on longevity}

Figure 4 shows the influence of lifetime $(I t)$ and disturbance on the minimal dispersal distance $\left(d_{\min }\right)$ allowing the pioneer to coexist with the climax. Exemplarily Figure $4 \mathrm{a}$ represents a low disturbance frequency $(N=1)$, whereas Figure $4 b$ shows a high disturbance frequency $(N=10)$. Analysis of the results showed that the dependency of $d_{\min }$ on lifetime can be described by:

$$
d_{\min }(I t)=d_{\min 1} * I t^{\mathrm{b}} \quad\left[d_{\min 1}=d_{\min } \text { for lifetime } 1 ; I t=\text { lifetime }\right] \quad \text { [3] }
$$

Note that, although the functional form is generally valid, $d_{\min 1}$ depends on the particular disturbance regime as shown above. The exponent $b$ determines the form of the curve. For light to moderate disturbance regimes, formula 3 is in a good agreement with the simulation results $\left(r^{2}>0.95\right.$, see Table 2 appendix) and for these cases $b$ is in a range between 0.5 and 0.7 . The narrow range means that $d_{\min }$ is approximately halved when lifetime is prolonged by three to four times. The predictability ( $r^{2}$ values) was better with longer lifetimes than with very short ones as well as for small disturbance diameters. For details see Table 2 in the appendix. 


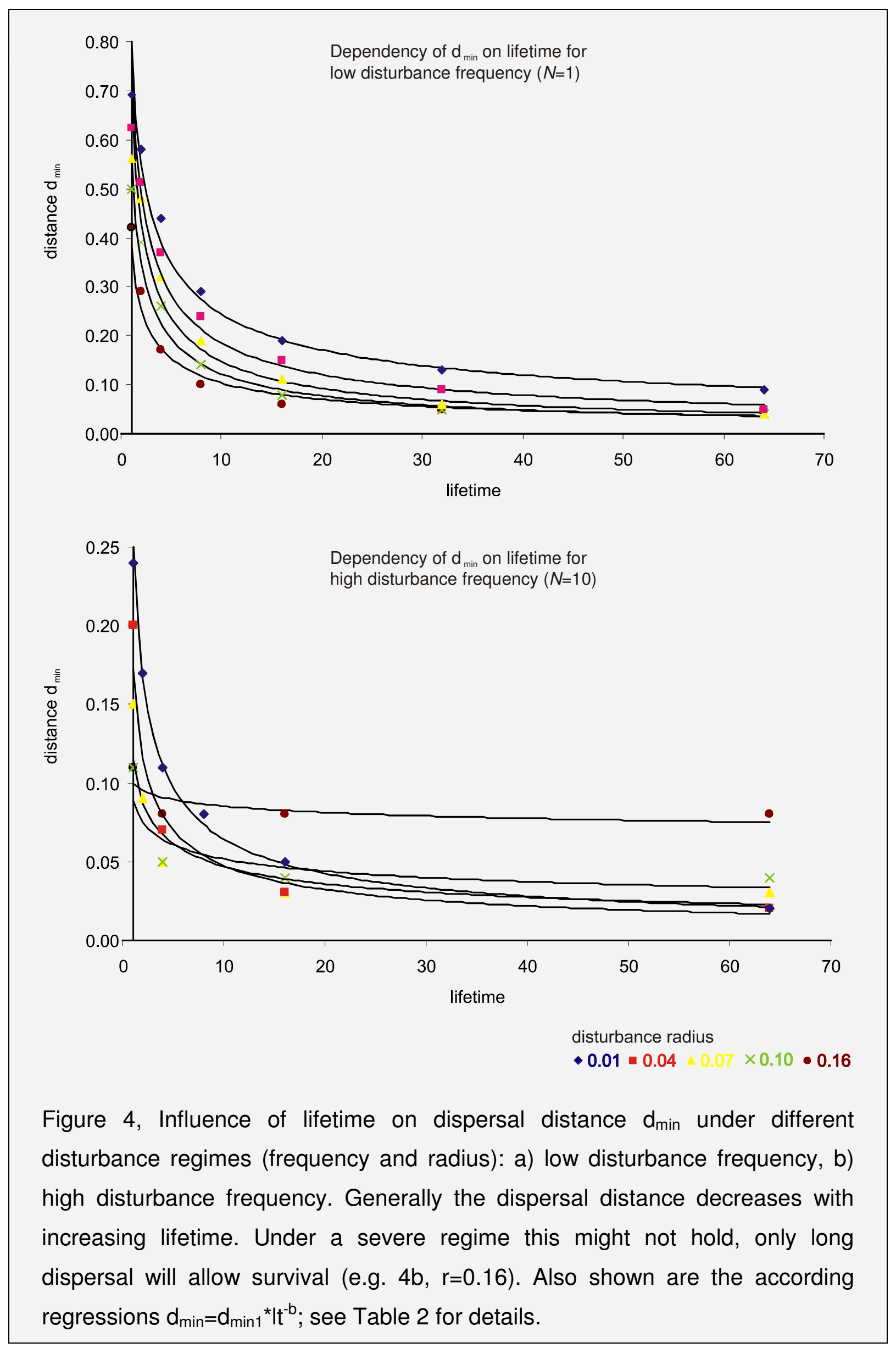




\subsection{Application of the results to the benthic assemblages of the Weddell Sea}

The Antarctic shelf is subject to disturbance events by grounding icebergs (Gutt et al. 1996). Based on the analysis of underwater video transects, Gutt and Starmans (2001) determined the disturbance regime for different locations in Antarctica. One region ('large iceberg bank') has an area of $300 \mathrm{~km}^{2}$ of which approximately $37.3 \%$ had been disturbed at last once in the last 15 years. An other region ('level plateau') contained less recently disturbed areas (7.3\% see Gutt and Starmans 2001 for details). Assuming a typical iceberg scour mark to be $500 \mathrm{~m}$ long and $120 \mathrm{~m}$ wide (see data in Hohmann 2002) this is equivalent to a total of 1,865 grounding events in this period or on average 124 events per year! Applying the same approach to the 'level plateau' region leads to only 24 events per year. These frequencies result in a mean distance between the centres of disturbed areas of about $782 \mathrm{~m}$ for the large

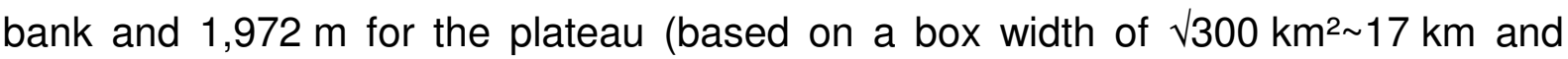
$D_{c}(124)=0.046$ and $D_{c}(24)=0.116$ respectively; see Eq. 2 ).

We want to apply our theoretical results to the benthic assemblages of the Antarctic. How far must a pioneer species disperse under the disturbance regime of the 'large iceberg bank' or the 'level plateau' to persist regionally? Teixido et al. (2004) analysed the biological succession after iceberg scouring and compiled a list of key species for different recolonisation stages. Among the very first sedentary pioneer organism are various polychaetes, bryozoans, gorgonians, sponges and some ascidians. For most species no detailed data on life-history traits exist. Comparatively well known is the solitary ascidia Molgula pendunculata Herdmann (1881). We have chosen this species, respectively its life-history traits, as characteristic for a pioneer of the Antarctic shelf. M. pendunculata show an fast growth and may reach an age of 3-12 years (Kowalke et al. 2001; Kühne 1997). It is a simultaneous hermaphrodite (Sahade et al. 1998) and is assumed to reproduce viviparously with short dispersal (Kühne 1997; Sahade et al. 1998; Svane and Young 1989).

An estimated average age of 6 years for $M$. pendunculata leads to a minimum dispersal less than $d_{\min }(124)=266 \mathrm{~m}$ for the large iceberg bank and $d_{\min }(24)=670 \mathrm{~m}$ for the plateau. Assuming an average current velocity of $0.05 \mathrm{~ms}^{-1}$ (see values for the shelf regions reported in Fahrbach et al. 1992), a dispersal phase of 90 min for the iceberg bank, respectively $225 \mathrm{~min}$ for the plateau, would be sufficient to cover these distances. 
The later successional stages are dominated by long-living species with budding or brooding behaviour (Teixido et al. 2004, Teixido in press). Such a species with an assumed age of 200 years needs a minimum dispersal of less than $d_{\min }(124)=31 \mathrm{~m}$ on the bank and $d_{\min }(24)=79 \mathrm{~m}$ on the plateau if dependend on recruitment in recently disturbed areas. These distances can easily be covered by budding or brooding species (Grantham et al. 2003) with a dispersal phase of a few minutes to less than half an hour.

\subsection{Discussion}

\subsubsection{The Simulation Model}

Using a simulation model we studied first the mean spacing of disturbed areas in a landscape as a function of a disturbance regime (frequency and size/radius). In a second step we showed that the minimum dispersal distance $d_{\text {min }}$ needed for the persistence and the coexistence of a pioneer species with a superior climax assemblage, is strongly related to the mean spacing of disturbed areas and thus to the disturbance regime.

At low disturbance rates the dispersal distance $d_{\text {min }}$ needed for persistence is slightly higher than the mean distance between the borders of nearest disturbed areas $D_{B D}$ (Figure 3). The parallel progression of $d_{\min }$ and $D_{B D}$ for small disturbance radii is conspicuous. With increasing size (or frequency) of the disturbances, $d_{\min }$ falls quasi parallel to $D_{B D}$ as the disturbed areas become closer to each other and dispersal from disturbance to disturbance is possible with a smaller dispersal distance. $d_{\min }$ reaches its minimum when $D_{B D}$ approaches zero, in other words, when the disturbances are so frequent that the disturbed areas start to overlap statistically. A further increasing disturbance regime, however, stops the decrease in $d_{\min }$ and leads to an increase again. This is due to the resulting landscape dynamics and the high mortality risk that demand higher dispersal distances for persistence of any species (Johst et al. 2002). At a certain disturbance intensity, the whole area is completely disturbed each time step and neither species can persist.

The resulting $u$-shaped form of $d_{\text {min }}$ brings together theoretical knowledge of species interactions and species persistence in dynamic landscapes. With weak disturbances, competition among species demands a high dispersal potential or other 
trade-offs for pioneers to be able to coexist with a superior species (Durrett and Levin 1998; Snyder and Chesson 2003).

Besides the disturbance regime, the second determinant of $d_{\min }$ is the species lifetime. As expected, with increasing lifetime $d_{\min }$ decreases (Figure 4). However, two things are important. First, the trade-off is nonlinear and has a hyperbolic form. This hyperbolic relationship means that a species can survive with halved dispersal distance if it has a lifespan that is three to four times longer. Furthermore, the greatest relative differences in dispersal distance exist between short-lived species. The older species become, the smaller the differences in required dispersal distances can be and, consequently, the less important the potential for far dispersal becomes (Figure 4a). Secondly, the dependence of dispersal distance on the lifetime is strong when the disturbance regime is light to moderate (Figure 4a) but breaks down when the regime is too severe (Figure $4 b$ ). Under a strong disturbance regime $d_{\min }$ is generally low and may not decrease with lifetime - instead it is constant or even increases (Figure 4b, e.g. $r=0.16$ ).

The absolute competitive superiority of the climax assemblage, especially its ability to acquire all the space not colonised by the pioneer, regardless of how far it is from any climax cell is a very rigorous assumptions. If the competitive strength of the climax species is weaker, a smaller dispersal distance than our predicted $d_{\min }$ would allow persistence. Furthermore, iceberg scours are rectangular rather than circular. However a circle has the smallest diameter to area relationship of all geometric figures. Disturbances of the same area but of a different shape would be closer together, thus requiring less dispersal.

For the 'large iceberg bank' region with frequent scouring the order of magnitude calculated for the spacing of the disturbed areas correlates well with a map of scour marks of this region in Hohmann (2002). For the 'level plateau' region with infrequent scouring unfortunately no data are available, but we believe our approach is able to present the properties correctly. Therefore, our results serve as a worst-case scenario i.e. our $d_{\min }$ is an upper limit for the ecologically necessary dispersal distance. Dispersal distances higher than $d_{\min }$ are not primarily designed to ensure regional survival with minimised dispersal cost but to conform to other ecological needs. 


\subsubsection{Relevance for the Antarctic communities}

Applying the model results to the benthic assemblages of the Weddell Sea lead to the conclusions that a dispersal phase of 1.5-4 hours is enough for a pioneer species like $M$. pendunculata to persist regionally due to the high disturbance regime and current speed. As stated above, these distances are an estimate for the upper limit distances needed for regional persistence. The actual dispersal distances could be smaller when some pioneer individuals are scattered within the climax and could serve as a stepping stone for the colonisation of distant habits. With high tidal current speeds up to $0.7 \mathrm{~ms}^{-1}$ (Fahrbach et al. 1992) dispersal distances up to as much as 5$10 \mathrm{~km}$ are possible. This might even be sufficient to explain a circumpolar distribution after the last glacial period (compare values for distance in Gutt 2000).

The pelagic larvae observed in the Antarctic waters (see introduction) belong mainly to potential pioneer phyla listed by Teixido et al. (2004). Recently Bowden (2005) published data on settlement experiments at Ryder Bay, (Antarctic Peninsula) and reviewed the currently available literature on similar experiments in Antarctic waters. However this data contains only information about the arrival of species and were conducted in shallow areas. Dispersal distances are still unknown for most species, especially for those from the continental shelf. Genetic markers may provide insights in the dispersal processes in the future but to day only theoretical approaches exists. It is commonly assumed that true pioneer species should depend on a long-range dispersal. However, due to the disturbance regime and their comparably long lifetime, the Antarctic species seem to be able to cope with rather short dispersal distances when compared with species from temperate or tropical regions. Our model does not explain why broadcasters like Sterechinus neumayeri have a pelagic phase of up to 120 days (Bosch et al. 1987). Even some of the key species of the later successional stages are assumed to be mid- to long-range dispersers (see Teixido et al. 2004). One reason might be simply slower development and thus longer pelagic phases in cold waters (Bosch et al. 1987). The capacity for long-range dispersal however pays off when the habitat is fragmented and strongly dynamic or strong competition occurs. Coral reefs provide a good example, as many long-living corals disperse through true mesoplanktonic larvae (Connell et al. 2004) and suitable shallow, temperate habitats are patchily distributed and limited in terms of space (Muko et al. 2001) when compared to the more or less homogeneous Antarctic shelf. 
However, in the last glacial periods the Antarctic shelf was nearly completely covered with ice and suitable habitats were rare. One assumption is that species moved to the upper parts of the continental slope (for further literature see Gutt 2000). Recently Thatje et al. (2005) supposed that survival was even not possible on the slopes (due to sediment and turbidity flows) and species had to migrate down into the deep sea. However, some areas under the ice may have provided some sheltered refuges or isolated island habitats. It must be expected that such a spatial separation fostered allopatric speciation in Antarctica during glacial periods. In such fragmented but at least temporally constant environments short dispersal is advantageous (Bolker and Pacala 1999) as it allows large local stocks to be built up. But species relying only on short dispersal have to face a high risk of extinction when the environment changes (Johst et al. 2002). A bimodal means of dispersal (short- as well as long-range dispersal) would be more beneficial, as this would enable the benefits of local dispersal as well as allowing distant habitats to be explored. Species could dominate confined areas and would be still able to jump from one sheltered island to another. At the beginning of an interglacial period recolonisation of the shelf would also be fostered by an establishment in a former inaccessible habitat enabled by long distance dispersal, followed by a quick domination due to mass recruitment mediated by short dispersal. This can lead to a strong founder effect with consequences for evolution, e.g. the separation of sibling or cryptic species.

Clonal organisms like sponges have such a second dispersal mode as they are able to disperse by fragments (Jackson 1986, Teixido in press), e.g. lifted up by anchor ice or rafting on the fragments eroded from iceberg keels (Dayton et al. 1969; Gutt 2001). The achieved dispersal distances typically exceed the normal dispersal distances by considerable magnitudes (Jackson 1986). The importance of such an unusual mode of dispersal for biodiversity is known (Higgins et al. 2003; Jackson 1986).

The suitability of long-distance dispersal (or its absence) might explain some features the observed community structure e.g. the dominant role of clonal organisms, especially sponges (Gatti 2002), and the extinction of other groups in Antarctica. Thorson's rule, a decline in planktotrophic larvae towards the poles may be explained, at least partially, by strong seasonal primary production and a resulting food limitation in these regions or by special habitat features (Gallardo and Penchaszadeh 2001). However our results suggest that long-distance dispersal, and 
thus a long pelagic larval phase, is not needed for regional coexistence under current environmental conditions. In the Antarctic the disturbance regime with a moderate reoccurrence frequency leads to a mosaic of different habitats. Regular reoccurrence superposes local competition and the relative proximity of habitats possibly eliminates the need for long-distance dispersal. Thus our results may present an additional explanation for the relative rarity of planktonic larvae in the Weddell Sea.

Acknowledgements

We thank Dr. S.Thatje for the discussions and comments that helped to improve the manuscript. 


\subsection{Appendix}

Table 1, Dependency of $d_{\min }$ on disturbance regime; lifetime $=1$

$\mathrm{d}_{\min }=a x^{3}+b x^{2}+c x+d ; \quad x=$ disturbance radius;

Lifetime $=1$

\begin{tabular}{l|l|l|l|l|l} 
& $\mathrm{a}$ & $\mathrm{b}$ & $\mathrm{l}$ & $\mathrm{d}$ & $\mathrm{r}^{2}$ \\
\hline $\mathrm{d}_{\min }(1)$ & 1.8720 & 2.1734 & -2.4757 & 0.7390 & $>0.99$ \\
\hline $\mathrm{d}_{\min }(2)$ & 8.3652 & -0.8773 & -1.7530 & 0.5668 & $>0.99$ \\
\hline $\mathrm{d}_{\min }(5)$ & 15.0880 & 0.1764 & -1.8356 & 0.3806 & $>0.99$ \\
\hline $\mathrm{d}_{\min }(10)$ & 14.2940 & 4.4379 & -2.0458 & 0.2638 & $>0.99$ \\
\hline $\mathrm{d}_{\min }(20)$ & 18.203 & 7.9288 & -2.0113 & 0.1807 & $>0.99$ \\
\hline
\end{tabular}

(note $d_{\min }(20)$ not shown in the graph; values supplied for convenience)

Table 2, Dependency of $d_{\min }$ on lifetime $\mathrm{d}_{\min }=\mathrm{d}_{\min 1}$ * lifetime ${ }^{-\mathrm{b}}$

\begin{tabular}{|c|c|c|c|}
\hline radius & $\mathrm{d}_{\min 1}$ & b & $r^{2}$ \\
\hline 0.01 & 0.7931 & 0.5125 & 0.9884 \\
\hline 0.04 & 0.7628 & 0.6160 & 0.9795 \\
\hline 0.07 & 0.7008 & 0.6776 & 0.9829 \\
\hline 0.10 & 0.5615 & 0.6628 & 0.9858 \\
\hline 0.16 & 0.3797 & 0.5638 & 0.9475 \\
\hline
\end{tabular}

High disturbance frequency $N=10$

\begin{tabular}{|l|l|l|l|}
\hline radius & $\mathrm{d}_{\min 1}$ & $\mathrm{~b}$ & $\mathrm{r}^{2}$ \\
\hline 0.01 & 0.2539 & 0.5964 & 0.9952 \\
\hline 0.04 & 0.1723 & 0.5594 & 0.9657 \\
\hline 0.07 & 0.1150 & 0.3886 & 0.8475 \\
\hline 0.10 & 0.0888 & 0.2350 & 0.7669 \\
\hline 0.16 & 0.1000 & 0.0689 & 0.6000 \\
\hline
\end{tabular}




\subsection{Bibliography}

Absher, T. M., Boehs, G., Feijo, A. R. and Da Cruz, A. C. (2003) Pelagic larvae of benthic gastropods from shallow Antarctic waters of Admiralty Bay, King George Island. Polar Biol. 26:359-364

Arntz, W. E., Brey, T. and Gallardo, V. A. (1994) Anarctic zoobenthos. Oceanogr. Mar. Biol. Annu. Rev. 32:241-304

Barnes, D. K. A. (1995) Seasonal and annual growth in erect species of Antarctic bryozoans. J. Exp. Mar. Biol. Ecol. 188:181-198

Bhaud, M., Koubbi, P., Razouls, S., Tachon, O. and Accornero, O. (1999) Description of planktonic polychaete larvae from Terre Adélie and the Ross Sea (Antarctica). Polar Biol. 22:329-340

Bolker, B. M. and Pacala, S. W. (1999) Spatial moment equations for plant competition: Understanding spatial strategies and the advantages of short dispersal. Am.Nat. 153:575-602

Bosch, I., Beauchamp, K. E., Steele, M. E. and Pearse, J. P. (1987) Development, metamorphosis, and seasonal abundance of embryos and larvae of the Antarctic sea urchin Sterechinus neumayeri. Biological Bulletin 173:126-135

Bowden, D. A. (2005) Seasonality of recruitment in Antarctic sessile marine benthos. Mar. Ecol. Prog. Ser. 297:101-118

Brey, T., Gutt, J., Mackensen, A. and Starmans, A. (1998) Growth and productivity of the high Antarctic bryozoan Melicerita obliqua. Mar. Biol. 132:327-333

Brown, K. M., Fraser, K. P. P., Barnes, D. K. A. and Peck, L. S. (2004) Links between the structure of an Antarctic shallow-water community and ice-scour frequency. Oecologia 141:121-129

Clarke, A. and Johnston, N. M. (2003) Antarctic marine benthic diversity. Oceanogr. Mar. Biol. Annu. Rev., Vol 41 41:47-114

Connell, J. H., Hughes, T. P., Wallace, C. C., Tanner, J. E., Harms, K. E. and Kerr, A. M. (2004) A long-term study of competition and diversity of corals. Ecol. Monogr. 74:179-210

Dayton, P. K., Robilliard, G. A. and Devries, A. L. (1969) Anchor ice formation in McMurdo Sound, Antarctica, and its biological effects. Science 163:273-274

Durrett, R. and Levin, S. (1998) Spatial aspects of interspecific competition. Theor. Popul. Biol. 53:30-43

Fahrbach, E., Rohardt, G. and Krause, G. (1992) The Antarctic costal current in the southern Weddell Sea. Polar Biol. 12:171-182

Fisher, R. (2005) Swimming speed of larval coral reef fishes: Impacts on selfrecruitment and dispersal. Mar. Ecol. Prog. Ser. 285:223-232

Gallardo, C. S. and Penchaszadeh, P. E. (2001) Hatching mode and latitude in marine gastropods: Revisiting Thorson's paradigm in the southern hemisphere. Mar. Biol. 138:547-552

Gatti, S. (2002) Die Rolle der Schwämme im hochantarktischen Kohlenstoff- und Silikatkreislauf - ein Modellierungsansatz. Report No. 434, Alfred-WegenerInstitute for Polar and Marine Research, Bremerhaven

Grantham, B. A., Eckert, G. L. and Shanks, A. L. (2003) Dispersal potential of marine invertebrates in diverse habitats. Ecol. Appl. 13:S108-S116

Gutt, J. (2000) Some "driving forces" structuring communities of the sublittoral Antarctic macrobenthos. Antarct. Sci. 12:297-313 
Gutt, J. (2001) On the direct impact of ice on marine benthic communities, a review. Polar Biol. 24:553-564

Gutt, J. and Piepenburg, D. (2003) Scale-dependent impact on diversity on Antarctic benthos caused by grounding icebergs. Mar. Ecol. Prog. Ser. 253:77-83

Gutt, J., Sirenko, B. I., Smirnov, I. S. and Arntz, W. E. (2004) How many macrobenthic species might inhabit the Antarctic shelf? Antarct. Sci. 16:11-16

Gutt, J. and Starmans, A. (2001) Quantification of iceberg impact and benthic recolonisation patterns in the Weddel Sea (Antarctica). Polar Biol. 24:615-619

Gutt, J., Starmans, A. and Dieckmann, G. (1996) Impact of iceberg souring on polar benthic habitats. Mar. Ecol. Prog. Ser. 137:311-316

Higgins, S. I., Nathan, R. and Cain, M. L. (2003) Are long-distance dispersal events in plants usually caused by nonstandard means of dispersal? Ecology 84:1945-1956

Hohmann (2002) Qualitative und quantitative Untersuchung von Eisbergpflugspuren im Bereich Austaasenbank (Antarktischer Schelf). Diplomarbeit, Hochschule für angewandte Wissenschaften Hamburg

Jackson, J. B. (1986) Modes of dispersal of clonal benthic invertebrates: Consequences for species distributions and genetic structure of local populations. Bull.Mar.Sci. 39:588-606

Johst, K., Brandl, R. and Eber, S. (2002) Metapopulation persistence in dynamic landscapes: The role of dispersal distance. Oikos 98:263-270

Jones, G. P., Planes, S. and Thorrold, S. R. (2005) Coral reef fish larvae settle close to home. Curr. Biol. 15:1314-1318

Kowalke, J., Tatian, M., Sahade, R. and Arntz, W. (2001) Production and respiration of Antarctic ascidians. Polar Biol. 24:663-669

Kühne, S. (1997) Solitäre Ascidien in der Potter Cove (King George Island, Antarktis). Ihre ökologische Bedeutung und Populationsdynamik. Report No. 252, Alfred Wegener Institute for Polar and Marine Research, Bremerhaven

Largier, J. L. (2003) Considerations in estimating larval dispersal distances from oceanographic data. Ecol. Appl. 13:s71-s89

Mileikovsky, S. A. (1971) Types of larval development in marine bottom invertebrates, their distribution and ecological significance: A re-evaluation. Mar. Biol. 10:193-213

Muko, S. and Iwasa, Y. (2000) Species coexistence by permanent spatial heterogeneity in a lottery model. Theor.Popul.Biol. 57:273-284

Muko, S., Sakai, K. and Iwasa, Y. (2001) Dynamics of marine sessile organisms with space-limited growth and recruitment: Application to corals. J. Theor. Biol. 210:67-80

Ragua-Gil, J. M., Gutt, J., Clarke, A. and Arntz, W. E. (2004) Antarctic shallow-water mega-epibenthos: Shaped by circumpolar dispersion or local conditions? Mar. Biol. 144:829-839

Roughgarden, J., Gaines, S. and Possingham, H. (1988) Recruitment dynamics in complex life cycles. Science 241:1460-1466

Sahade, R., Tatian, M., Fernanda, M. and Esnal, G. B. (1998) Seasonality in reproduction of Antarctic ascidians (Molgula pedunculata, Cnemidocarpa verrucosa and Pyura setosa). Report No. 299, Alfred Wegener Institute for Polar and Marine Research, Bremerhaven

Sewell, M. A. (2005) Examination of the meroplankton community in the southwestern Ross Sea, Antarctica, using a collapsible plankton net. Polar Biol. 28:119-131 
Shanks, A., Grantham, B. and Carr, M. (2003) Propagule dispersal distance and the size and spacing of marine reserves. Ecol. Appl. 13:S159-S169

Shreeve, R. and Peck, L. (1995) Distribution of pelagic larvae of benthic marine invertebrates in the Bellingshausen Sea. Polar Biol. 15:369-374

Snyder, R. E. and Chesson, P. (2003) Local dispersal can facilitate coexistence in the presence of permanent spatial heterogeneity. Ecol. Lett. 6:301-309

Stanwell-Smith, D. P., Peck, L. S., Clarke, A., Murray, A. W. A. and Todd, C. D. (1999) The distribution, abundance and seasonality of pelagic marine invertebrate larvae in the marine Antarctic. Phil.Trans.R.Soc.Lond.B 354:471484

Svane, I. and Young, C. M. (1989) The ecology and behaviour of ascidian larvae. Oceanogr. Mar. Biol. Annu. Rev. 27:45-90

Teixido, N., Garrabou, J., Gutt, J. and Arntz, W. E. (2004) Recovery in Antarctic benthos after iceberg disturbance: Trends in benthic composition, abundance and growth forms. Mar. Ecol. Prog. Ser. 278:1-16

Teixido, N., Gili, J.-M., Uriz, M. J., Gutt, J. and Arntz, W. (in press) Observations of sexual reproductive strategies in Antarctic hexactinellid sponges from ROV video records. Deep-Sea Res.

Thatje, S., Hillenbrand, C.-D. and Larter, R. (2005) On the origin of Antarctic marine benthic community structure. Trends Ecol.Evol. 20:534-540

Tilman, D. (1994) Competition and biodiversity in spatially structured habitats. Ecology 75:2-16

Todd, C. D. (1998) Larval supply and recruitment of benthic invertebrates: Do larvae always disperse as much as we believe? Hydrobiologia 375/376:1-21 